Ssciendo Studia Anglica Posnaniensia 54 (2019): 81-112

doi: 10.2478/stap-2019-0005

\title{
ON INTENSIVE ENDOPHORIC DEVICES IN ENGLISH*
}

\section{DIEGO KRIVOCHEN ${ }^{1}$}

Memories are what our reason is based upon... if we can't face them, we deny reason itself!

The Joker

(Alan Moore, Batman: The Killing Joke. 1988)

\section{ABSTRACT}

This paper deals with the syntactic and semantic properties of a specific kind of anaphoric device (AD) in English, instantiated by Prn+SELF lexical items (himself/herself/itself...; 'SELF' henceforth), which do not behave like anaphors in the sense of Binding Theory either syntactically or semantically. These devices have received the name of intensives in the grammatical literature (Leskosky 1972; Siemund 2000, among many others). We will look at the syntactic behaviour of so-called intensives in different syntactic contexts, and refine the classification of these ADs taking into consideration (a) how each type of intensive is derived, (b) the kinds of syntactic rules that can affect them, and (c) their meaning.

Keywords: Anaphora; reflexivity; intensives; classic transformational grammar.

\section{Introduction}

Consider the examples in (1):

1) a. John admires himself

b. John wrote the paper himself

c. John himself wrote the paper

* We would like to thank Cynthia Allen, Emma Pilkington, Haj Ross, Doug Saddy, two anonymous SAP reviewers, and especially Susan F. Schmerling for their grammaticality judgments, challenges, and insightful comments, which we have tried our best to address. The usual disclaimers apply.

1 Università di Verona, Viale dell’Università 4, 37129 Verona, diegokrivochen@hotmail.com 
(1a) is an example of garden-variety reflexive anaphora; it realises an argument of a transitive predicate and is bound within its governing category. The referential dependency is, in a sense, anti-local, because the $\mathrm{AD}$ and its antecedent are not contained in the same minimal XP. In garden-variety anaphora like (1a), the interpretation is reflexive, such that the admirer and the admiree are coindexed. This is the kind of AD that appears, grosso modo, with both transitive and intransitive Vs, including obligatory reflexives as in 'pride oneself on' (Quirk et al. 1985: 357-358).

Immediately we see that $(1 \mathrm{~b})$ is a different kind of creature. While the relation between the AD and its antecedent is anti-local in the sense specified above, the interpretation is not reflexive: there is no event for which John is both agent and patient ${ }^{2}$. 'Himself' does not realise an argument of 'write', whose c- and sselectional properties are already satisfied by 'John' and 'the paper'.

Similarly, (1c) cannot be assimilated to usual anaphora: firstly, it is bound too locally, that is, the $\mathrm{AD}$ and its antecedent are both contained within the minimal $\mathrm{XP}$ that contains the AD. Secondly, and as in the previous case, the AD does not realise an argument of the $\mathrm{V}$, thus, there is no reflexive relation.

\section{Some previous perspectives}

ADs like the ones we find in (1b) and (1c) have been looked at in the literature (although much less than their garden-variety counterparts). Siemund (2000: $\S 1.1)$ presents a variety of takes on what these creatures are from a comparative perspective (English vs. German); the scope of the present paper is much more limited (focused on the syntax of these AD in contemporary English). However, some minimal background is necessary to find the niche for our inquiry:

- Some authors refer to the ADs in (1b-c) as Locally Free Reflexives, like Baker (1995). Specifically, Baker refers to such ADs as 'contrastive prominent' variations of Locally Free Reflexives, a term that encompasses any SELF AD which "fails to have as its antecedent a syntactically prominent NP that lies within the reflexive's local neighborhood" (1995: 64). Bickerton (1987) suggests that intensives (without making any further distinction) can be analysed as either [+ anaphoric] [+ pronominal] in a GB framework, or as analogous to picture-noun 'himself', based on their binding-theoretic properties. The kind of SELF that we see in (1b) would, presumably, have the same

The definition of reflexivity according to which an event is reflexive if two of its arguments are coindexed is somewhat simplified, but good enough for our purposes since we are focusing on a different phenomenon. See Reuland \& Reinhart (1993: 662ff.) for an extensive discussion. 
binding properties as the one in (1c) - the latter, the one on which Bickerton focuses his attention - being derived via Extraposition. Levinson (1991: 119) uses the term Long Range Reflexive and proposes a pragmatic account of their apparently anomalous status with respect to Binding Theory ('apparently' because it is only so if binding primitives refer to morpho-phonological form rather than to semantic-syntactic behaviour). The common aspect we want to highlight between Baker and Levinson is the use of reflexive in the designation of these endophoric devices, which is essentially misleading.

- Quirk et al. (1985: 360-361, 1399) group cases (1b) and (1c) under the label 'emphatic reflexives'. They do not explore the semantic differences between the two variants, but hold that their distribution is governed by information structure: if the sentence is to have end focus, the stressed reflexive will form a discontinuous NP with its antecedent. They do make an interesting syntactic observation (to which we will come back): extraposing the apparent reflexive is possible only if it is linked to the subject, but not to an object, be it $\mathrm{DO}$ or $\mathrm{IO}^{3}$ :

2) a. I showed Ian himself the letter

b. *I showed $\operatorname{Ian}_{i}$ the letter himself $f_{i}$

c. $\mathrm{I}_{i}$ showed Ian the letter myself $f_{i}$

d. *Mary said to Peter $_{i}$ [that she had proven the Riemann Conjecture easily] himself $f_{i}$ (for context, assume that Peter is a mathematician who, everybody knows, has devoted his entire life and career to proving the Riemann Conjecture with no success, and is very upset about it)

e. Mary said that she had proven the Riemann Conjecture easily to Peter himself (same context)

f. Mary said to Peter that she had proven the Riemann Conjecture easily herself

g. *?Mary said to Peter herself that she had proven the Riemann Conjecture easily

Note that, when extraposed (i.e., in the so-called adverbial distribution), the AD can appear after extraposed NPs. In both (2f) and (2g), relevantly, the intensive is intended to be linked to the event of saying, not of proving. Given the context provided in (2d), that is the only possible interpretation,

We will use the following symbols to indicate degrees of unacceptability, from ungrammatical to mildly awkward: *, *?, ?. \# will be used to indicate that a sentence is awkward only if interpreted literally (i.e., awkward pragmatically). All sentences have been judged by native speakers of English, belonging to Southern UK, Southern US, and Canadian (Vancouver) varieties. 
although (as we will see below) if Peter had proven the Riemann Conjecture, it would be possible to interpret herself in 'adverbial' distribution as linked to the event of proving.

- König \& Gast (2002); Gast \& Siemund (2006) - among others - distinguish an adnominal and an adverbial variant of an 'intensive SELF', which is itself distinguished from reflexive anaphora. However, not much attention is paid to the syntactic behaviour of these forms, the focus being rather comparative and semantic in nature. The description of the semantic values of (1b) and (1c) in their terms is as follows: the adnominal version (1c) is a mere identity function scoping over a referential variable, such that -in their notation- N+SELF $=\operatorname{ID}(\mathrm{N})$. Combined with heavy nuclear stress, and as noted by Quirk et al. (1985:361), the meaning of N+SELF is ' $\mathrm{N}$ and nobody else', a contrastive interpretation with respect to other paradigmatic possibilities (Gast \& Siemund 2006: 349). Leskosky (1972) glosses the adnominal intensive as 'personally', and also as 'even' (situating the NP at an extreme within a scale):

3) The police questioned the President himself!

A good gloss for (3) is 'the very President' (modulo the archaic flavour of this gloss), which generates the implicature that the President was, probably because of his position, a very unlikely person to expect the police to question. Note, incidentally, that when the relevant NP fails to be at the extreme of a scale or hierarchy, acceptability drastically drops:

3') \#Enter the shop and talk to the clerk himself (cf. Enter the shop and talk to the owner himself)

Both 'personally' and 'even' as glosses for adnominal SELF concur with the aforementioned references. It makes sense, in this context, that indefinite NPs (including quantified NPs) cannot co-occur with intensives, because both glosses require picking out an entity out of a set. In the case of even, that set is structured as a scale, and the selected entity is an extreme on the said scale. First, let us illustrate the resistance of indefinites to appearing in the intensive construction:

4) a. *A man himself was at the door

b. *A man was at the door himself

c. ?A boy kissed every girl himself

d. ?Three boys themselves kissed every girl

e. ?Three boys kissed every girl themselves 
The examples in (4) show that stative unaccusative Vs, whose subject is a theme, seem to reject the intensive more forcefully than transitives with agentive subjects; we will come back to this shortly.

If, as Enç (1991: 2) notes, adjectives like specific or certain form specific NPs, then they should ameliorate the violations in (4), which they indeed do (compare (4c-e) with the following):

4') a. A certain boy (himself) kissed every girl (himself)

b. Three specific boys (themselves) kissed every girl (themselves)

The adverbial distribution was preferred by our informants, but the adnominal version was not deemed ungrammatical. But then again, we must note that not all definite NPs can license intensives. First-mention (non-specific) definites resist the intensive construction in most cases $(5 \mathrm{a}-\mathrm{b})$ :

5) a. *I entered the room and the light itself was turned on

b. *This car has a statue on the dashboard itself (adapted from Roberts, 2003: 290)

c. *You can go to that zoo and pet the monkey itself

d. ?Enter any classroom and the students themselves will know you are a professor

Note that the constraint against first-mention definites applies to both animate $(5 \mathrm{c}, \mathrm{d})$ and inanimate $(5 \mathrm{a}, \mathrm{b}) \mathrm{NPs}$, and in both subject (5a, d) and object $(5 \mathrm{~b}, \mathrm{c})$ position, although animates in subject position (5d) do sound significantly better than any of the other options. It is also relevant to point out that NPs which are indefinite in form but generic in meaning do accept the intensive (examples due to Susan Schmerling, p.c.):

6) a. A bloodhound itself couldn't trace this man's scent.

b. A university professor herself wouldn't know how to spell this word.

We will come back to cases like (6) below, because it is the genericity of the relevant NPs that makes all the difference.

When the NP is of the form the $+N$ there are further requirements to be met. The relevant one, we propose, seems to be for a specific NP, rather than a merely definite one (see Ioup 1977 and Enç 1991 for a development of this distinction; we will come back to it in Section 5). There is an additional preference for animate NPs for intensives, which correlates with the difference between the stative and dynamic predicates seen above: 
7) a. (\#)The computer itself finished all the work

b. *Three centuries themselves have passed since the battle

c. *The building itself collapsed after the hurricane

Note that (7a), when acceptable, necessarily involves an inferential anthropomorphisation of the computer; thus, the animacy preference is satisfied. When we have a dynamic ergative predicate (like collapse) there is nothing to license the anthropomorphisation that rescues (7a), and the result is ungrammatical, as with (7c). In the case of (7c), we need to note, there is an additional issue pertaining to the lack of specificity: an example like The White House itself collapsed after the hurricane works much better (arguably, the White House is an extreme in a scale of US buildings in terms of importance: there seems to be a scalarity effect in play); it is because of cases like this (to which we will return in Section 5) that we said 'preference'. We will see that this semantic restriction plays a role in the acceptability of the intensive in passive constructions.

Mutatis mutandis, in the case of (1b) - the adverbial distribution - the interpretation is not primarily contrastive within a paradigm; rather, the paraphrases proposed by König \& Gast (2002) are 'alone' or 'without assistance' (Gast \& Siemund 2006: 349 gloss these forms as indicating that the associated NP did not delegate the performance of the action denoted by the VP to someone else). That is, we are dealing with uniqueness and agency, not identity. In this context, it is not surprising that NPs that accept an anthropomorphised interpretation sound better with an associated adverbial intensive than with an adnominal intensive (i.e., (7'a) sounds better than (7a)):

7') a. The computer finished all the work itself

For (7'a) to work, however, we are forced to assume that the computer was an agent of the finishing of the work, which requires the aforementioned anthropomorphisation of the computer. The availability of the adverbial intensifier seems thus to be linked not only to the grammatical function played by the associated NP - which must be subject - but also to its thematic role which must be agent. Note that, because it is not possible to anthropomorphise three centuries, combined with the non-agentive $\mathrm{V}$ pass, (7b) cannot be rescued in the same way.

Not all accounts of intensive forms separate adnominal and adverbial intensives semantically. Leskosky treats the adverbial intensive as an extraposed adnominal intensive, without assigning any distinctive semantic value to it. We will come back to Leskosky's account in detail below. 
Neither Baker nor Quirk et al. question the label 'reflexive' for uses of SELF like (1b) and (1c), despite the fact that there are obvious semantic differences (and not so obvious syntactic differences) between (1a) on the one hand and (1b) and $(1 \mathrm{c})$ on the other. Leskosky does, however, and he is the first, to our knowledge, to study the syntactic behaviour of intensives as opposed to that of reflexives. Baker (1995: 64), in contrast, presents the following as examples of what he calls Locally Free Reflexives:

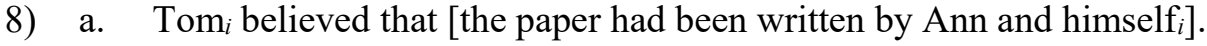

b. $\mathrm{John}_{i}$ thinks that [Mary is taller than himself ${ }_{i}$.

c. Mary ${ }_{i}$ complained that [the teacher gave extra help to everyone but herself $i$

There are, however, differences among these examples which make it difficult to argue that we are in the presence of a unified phenomenon, apart from the fact that the $\mathrm{AD}$ is bound outside its governing category (marked in square brackets) in all three cases. In (8a), the AD is not bound within its governing category (thus, it cannot be characterised as a garden-variety anaphor in Binding Theoretic terms) and it cannot be replaced by the pronominal AD 'him' while maintaining acceptability in many varieties of English (thus, it cannot be garden-variety pronominal in those varieties, either). In (8b), the AD is an argument of the binary relation 'taller than', which can be replaced by the pronoun 'him'. In (8c) the AD occurs within an adjunct phrase and can similarly be replaced by 'him'. In neither (1b) nor (1c) can the SELF AD be replaced by a pronoun. Crucially, if 'reflexivity' is a property of predicates rather than arguments (such that a predicate is reflexive if two of its arguments, the external and an internal argument, are coindexed, as proposed in Reuland and Reinhart 1993), then we are not in the presence of reflexivity in any of the examples in (8). All we have is a SELF form which is bound outside its governing category, but which for purposes of the Binding Theory (as formulated in Chomsky 1981: 188) behaves like a pronoun and is thus subject to Principle $\mathrm{B}^{4}$.

A provisional conclusion (by no means new) is, then, that not every morphological SELF is an anaphor in the sense of Principle A of the Binding Theory, nor is it semantically reflexive (or, more specifically, an argument of a reflexive predicate). The syntactic-semantic behaviour of a SELF form may not be reflexive (and, in principle, it does not need to be). Strictly speaking, however, all of the instances of SELF that we have encountered so far are endophoric referential devices; we will thus refer to the SELF in (1b) and (1c) as Endophoric Devices

$4 \quad$ But see Levinson (1991: 116ff.) for a non-syntactic perspective. 
(ED), and make a distinction between true reflexives and pseudo-reflexives ${ }^{5}$, the latter of which can be either adnominal or adverbial (König \& Siemund 2000; König \& Gast 2002; Gast \& Siemund 2006, among others).

In this vein, we will explore some aspects of the syntax and semantics of the ED in (1b) and (1c) in English.

3. Some syntactic tests: Pronouns, reflexives, and intensives

At this point, it is useful to provide syntactic evidence for the distinction between true reflexives and the kind of ADs that we are analysing here; we will do that by looking at their behaviour under specific transformations ${ }^{6}$. Unlike true reflexives, pseudo-reflexives cannot be topicalised or focalised unless as part of the phrase 'all by SELF'?

9) a. (Everyone admires someone else: Mary admires Susan, and Peter admires Bill, but) himself, only John admires (Topicalisation)

b. (Everybody pities lots of people, but) Only himself, only John pities

c. *Himself, John wrote the paper

d. All by himself, John wrote the paper

e. Only himself can John pity (Focalisation)

f. Not even himself would John allow to do that (Focalisation)

g. *Himself, only John could have done it this good (cf. Not even John himself could have done it this good)

True reflexives can be moved because, being arguments, they leave a gap in their base-generated position, which they bind from their derived position. The operation satisfies the requirement of unambiguous recoverability in the filler-

5 These include logophors as understood in Reuland \& Reinhart (1993); but not quite as the term is used in Safir (2004: 174). We will not get into the debate here over exactly what logophors are and what their relation is to discourse and subjective perspective.

$6 \quad$ Here I use the term "transformation" in its accepted mathematical sense - the source of its use in syntactic theory, historically - to designate a relation between a set of inputs and a set of permissible outputs with the property that each input is related to exactly one output (transformations are thus single-valued functions), with such variations as will prove necessary as the paper proceeds. Nothing further is implied in my use of this term.

7 However, Quirk et al. (1985: 361) offer the following examples of archaic literary uses of what seems to be an intensive in subject position:

(i) Myself is thus and so, and will continue thus and so. (Bellow)

(ii) Oneself did not die; that, like the very quiddity of otherness, was for others. (Burgess) It has been suggested to us by Susan Schmerling (p.c.) that these forms are not intensives, but rather pronouns (which would make (i) and (ii) parallel to the examples in (8)); the relevant condition here being that in contemporary English pseudo-reflexives cannot function as subjects. 
gap relation, such that there is only one possible deep structure for $(9 a)$, which is (9a') (here we simplify matters a bit by ignoring the problem of exactly when in a derivation the quantifier is inserted:

9 a') Only John admires John

with the lowest John becoming himself via Reflexivisation (in the sense of Lees and Klima 1963; see Section 4 below).

9 a") Only John admires himself

And then, himself is fronted by Topicalisation, yielding (9a).

Let us now analyse what would happen in a counterfactual scenario, to see why himself in (9a) cannot be an intensive. If the ED was linked to the NP John as an intensive - as opposed to being linked to the gap licensed by the movement of the intensive from the position immediately following the transitive $\mathrm{V}$ admire - some problems would arise. First, there would be an unbound gap, indicated with $e$, in the complement position of the $\mathrm{V}$ admire:

9 a"') Himself $f_{i}$, only John $t_{i}$ admires $e$ (intensive in adnominal distribution)

Second, and again, if we were dealing with an intensive, we would actually have to consider two possible Deep Structures for ( 9 a"'):

9"') a. Himself $i$, only John $t_{i}$ admires $e$ (adnominal)

b. Himself $i_{i}$, only John admires $e t_{i}$ (adverbial)

This is a problem because, if the endophoric device was linked to John as an intensive (in either distribution), there would be no way of determining the semantic interpretation of (9a), contrary to fact. (9a) can only be interpreted as containing an anaphoric himself (a true reflexive), and only these (and not pseudoreflexives) can be fronted. In our original scenario, the number of deep structures for (9a) is correctly limited to one (which makes it possible to formulate deterministic unambiguous reconstruction procedures as part of the grammar).

Moreover, the presence of a gap in the structure immediately blocks the intensive reading:

10) Himself, only John could admire 
The only possible Deep Structure for (10) is (10'a), and not (10’b)

10') a. Only John could admire himself

b. *Only John himself could admire $[e]$

Once we identify the fact that the fronted element is an NP argument, we expect dependencies to be clause-bound and subject to the usual constraints on movement (Ross 1967 and much subsequent work)

11) *Himself $i$, only John could admire the boy who $i$ disgraced $t_{i}$ (Complex NP Constraint violation)

Even when a pseudo-reflexive appears in adnominal position, fronting (e.g., Topicalisation, left dislocation) is blocked:

12) a. *He himself $i, \mathrm{John}_{i}$ murdered Bill in cold blood

b. *John himself ${ }_{i}$, he $_{i}$ murdered Bill in cold blood

Note that the non-dislocated version is grammatical:

12') John himself murdered Bill in cold blood

(12a, b) contrast with the usual examples of left dislocation, as in (13):

13) My sister $i$, she $_{i}$ knows a lot about art

where there is no intensive and the result is grammatical.

There is, however, the possibility of topicalising a non-argument SELF if and only if it is coindexed with a $1^{\text {st }}$ person Nominative argument:

14) Myself, I wouldn't let John take charge in a million years

However, it is not clear that (14) derives from either $\left(14^{\prime}\right.$ a) or $\left(14^{\prime} b\right)$ at all:

14') a. I myself wouldn't let John take charge in a million years

b. I wouldn't let John take charge in a million years myself

The reason is that these are not adequate paraphrases of each other. (14) would be better paraphrased as 'As far as I am concerned, I wouldn't...' or 'If I were you, ...', rather than as 'I, as opposed to everybody else...'? we think there is no paradigmatic contrast as part of the meaning of (14) (although it can arise as a conversational implicature in the sense of Grice 1975), whereas identity and contrast are, all authors agree, part of the meaning of the intensive in (14'a). As far as (14'b) is concerned as a paraphrase of 
(14), there seems to be no uniqueness and agency in (14) except, again, as a conversational implicature. If this is indeed the case, then there are reasons not to consider (14) a topicalised (i.e., leftwards-moved) adnominal or adverbial intensive; rather, it could be a base-generated 'free topic'. An argument in favour of this view is that some varieties of English allow for the SELF form to surface as a pronoun:

14") Me, I wouldn't let John take charge in a million years

In which case we are, again, in the presence of an element governed by Principle B. If this is indeed the case, then (14) does not constitute a counterexample to the generalisation that intensives cannot be topicalised (as long as cannot be topicalised is not equated to cannot be topics: the former condition establishes that they cannot become topics by means of syntactic transformations).

There is a variant structure with [all by+SELF], which could be interpreted as an analytic version of the adverbial SELF (insofar as it highlights uniqueness, without the construction having a contrastive meaning):

15) All by himself $f_{i} \mathrm{John}_{i}$ murdered Bill in cold blood

a. *All by John, he murdered Bill in cold blood

b. *All by John himself, he murdered Bill in cold blood

c. *All by him, John murdered Bill in cold blood

As long as the subject of the clause is a definite NP (see above), the only acceptable combination is [all by $+\mathrm{SELF}]$ coindexed with the subject:

17) $\mathrm{John}_{i}$ murdered Bill $l_{j}$ in cold blood all by himself $f_{i / *_{j}}$

The requirement that intensive SELF be coindexed with the subject is strong enough to negate any Superiority effects ${ }^{8}$ : the potential binder Bill, which is structurally closer to himself than John is, cannot, however, be linked with the ED 9 .

8 As a reminder, Superiority is defined as follows (Chomsky 1977: 101):

Superiority Condition

No rule can involve $X, Y$ in the structure

...X...[a...Z...-WYV-...] ...

where the rule applies ambiguously to $Z$ and $Y$ and $Z$ is superior to $Y$.

9 We need to address a reviewer's comment pertaining to the notion of structural closeness that is relevant here. Let the subject be a daughter of S. The NP 'Bill' is the complement of V, and 'all by himself' is adjoined to VP. 'Bill' and 'himself' are therefore both transitively dominated by the same maximal projection (namely, VP), which excludes the NP 'John' (see, e.g., Chomsky \& Lasnik 1995: 44). 
The interaction between pseudo-reflexives and pronouns can be seen in (18):

18) a. * $\operatorname{John}_{i}$ criticised himi

b. John criticised himself

c. $\mathrm{John}_{i}$ himself $_{i}$ criticised him $*_{i j}$ (where $j$ is exophoric)

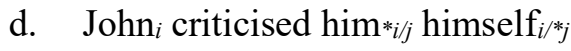

We already noted (following Quirk et al. 1985) that the adverbial variant of the intensive pseudo-reflexive cannot be coindexed with an accusative object; the examples in (19) are ungrammatical:

19) a. *I gave $\operatorname{Ian}_{i}$ the letter himself $i$

b. *John told Mary $i$ [that Peter had won the scholarship] herself $f_{i}$

Adnominal pseudo-reflexives have a wider distribution, appearing in both Nominative and Objective contexts. However, Leskosky (1972: 47) observes that neither adnominal nor adverbial can appear in Genitive contexts:

20) a. *This is Lyndon's himself barbecue pit (Leskosky's (20))

b. *This is Lyndon's barbecue pit himself

c. *This is Lyndon himself's barbecue pit

The restrictions, thus, are ordered as follows (where ' $>>$ ' = 'establishes stronger restrictions than'):

21) Genitive (neither adnominal nor adverbial) $>>$ Objective (only adnominal) $>>$ Nominative (both adnominal and adverbial)

However, grammatical function is not the only factor to consider where the distribution of the forms is concerned. Take a look at (22):

22) a. Which picture of himself did John say Mary likes?

b. Which picture did John himself say Mary likes? $(\neq 22 \mathrm{a})$

c. *Which [picture of himself] did $\mathrm{John}_{i}$ say Mary likes $t$ himself $i$ ? (cf. John himself said Mary likes this picture of himself)

Leskosky (1972: 48) proposes that the adverbial variant is derived by means of an operation of Extraposition, which "cannot take place unless the intensive and its antecedent are in the subject position" - a generalisation we will refer to as the 'subject condition'. If this was the case, then (22c) could incorrectly be predicted to be grammatical, since the antecedent John is in subject position, 
and so would himself have been before Extraposition. The generalisation seems to be roughly correct in spirit, but insufficient. As it stands, the restrictions in (21) are not accounted for. There are also problems when we consider passives: when does the subject constraint apply? If at deep structure (at a derivational point before the application of transformational rules), then we should get adverbial intensives coindexed with by-phrases (which we don't, see (23'b) below), because before Passivisation, the relevant NPs are subjects. If at surface structure, then we cannot, because after Passivisation, the relevant NPs are no longer subjects. We will now get into this problem of rule ordering and their interaction with the subject constraint. There are some rules with respect to which Leskosky considers ordering the rule of Intensive Extraposition: Passivisation and Flip ${ }^{10}$. Let us see:

23) Mary gave John himself a diploma

a. *Mary gave John a diploma himself (via Extraposition)

b. *John was given a diploma himself by Mary (via Passivisation)

23') Mary herself gave John a diploma after the graduation ceremony

a. John was given a diploma by Mary herself after the graduation ceremony (via Passivisation)

b. *John was given a diploma by Mary after the graduation ceremony herself (via Extraposition)

This ordering does not seem to work. Applying the two operations in the order Extraposition > Passivization gives rise to illegitimate sequences. Let us see the opposite order:

24) a. John himself was given a diploma by Mary (via Passivisation)

b. \#John was given a diploma by Mary himself (via Extraposition)

And this (Passivisation $>$ Extraposition) is the ordering that Leskosky proposes. However, we will need to come back to (24b), because as it stands, it is not quite acceptable. We will see below that there is a way to save (24b), but that will

10 'Flip', also known as 'subject-object inversion' (Lakoff 1965: a-15) or 'Psych Movement' (Postal 1971) is a lexically governed rule which, roughly speaking, switches the positions of Deep subjects and objects. Flip-verbs "have underlying Experiencer subjects and sentential objects" (Ross 2012: 16), NPs, or free relative clauses (thus, NPs). Others denote sensory perception, and in these cases both subject and object can be NPs. The rule is obligatory for some of these verbs (e.g., surprise, amuse), and optional for others (e.g., benefit, profit), as in (i) and (ii) respectively:

(i) *I surprised (at) that you won $\Rightarrow$ That you won surprised me

(ii) I benefitted from the market crash $\Rightarrow$ The market crash benefitted me 
require abandoning the assumption that the SELF that appears there is derived via Extraposition.

As for Flip (Lakoff 1965: A-15; Ross 2012: 16), we can see the following examples (all taken from Leskosky 1972: 48):

25) a. Mary was amused at John himself

b. John is amusing to Mary himself

c. John himself is amusing to Mary

We have not been able to find informants to whom all three examples yield grammatical and acceptable intensive readings (against Leskosky's own judgments). (25c) was rather widely accepted, but without further context, it was deemed awkward. Interestingly, it was impossible for our informants to assign an intensive reading to (25b): its interpretation was completely different and also required further context. As a matter of fact, the instance of SELF that we find in (25b), we argue, is a different creature from both adnominal and adverbial intensives; we will come back to this (and to (24b)) in Section 5 below.

\section{A classical derivation for intensives}

Let us now examine some aspects of the derivation of adnominal and adverbial intensives, expanding on the proposal in Leskosky (1972). We will make use of a generative theoretical apparatus which allows us to make transformations (used here as theory-neutral descriptive devices) fully explicit: we want to be able to describe what happens to what elements in which structural descriptions and which configurations arise as a result, as well as formulate and test concrete hypotheses pertaining to the ordering of the relevant transformations. In what follows, late capital letters (X, Y, Z) are variables in the sense of Ross (1967), to each of which an integer is assigned that allows us to track their position in structural descriptions and structural changes.

In this context, we assume an optional Reduplication rule of the general form proposed (in a different context) by Schmerling (2018: 4):

Reduplication: $\begin{array}{ccc}\mathrm{X} & -\mathrm{NP} & -\mathrm{Y} \\ 1 & 2 & 3 \\ 1, & 2+2, & 3\end{array} \Rightarrow$

The crucial caveat here is that Reduplication does not form a lexical terminal. If this is so, then the reduplicated $\mathrm{N}$ can be further affected by Pronominalisation, in the generalised formulation we find in Bach (1970): 
An $\mathrm{NP}_{1}$ may pronominalize an identical $\mathrm{NP}_{2}$ if $\mathrm{NP}_{1}$ is to the left of $\mathrm{NP}_{2}$ under any conditions, or if $\mathrm{NP}_{1}$ is to the right of $\mathrm{NP}_{2}$ and $\mathrm{NP}_{2}$ does not command $\mathrm{NP}_{1}$

(Bach 1970: 121)

The derivation we propose, then, would take a specific NP and reduplicate it, the result then being sister-adjoined to the original NP. Then, Pronominalisation (more specifically, Reflexivisation) transforms the reduplicated NP into a reflexive form. All in all, we could use the original Lees-Klima (L\&K) formulation of the Reflexive rule (which has been taken up in more recent works; see, e.g., Reinhart (1983) and the 'chain-based' approach to Binding in Hornstein \& Idsardi 2014: 15):

Reflexive Rule: X-Nom-Y-Nom'-Z $\rightarrow$ X-Nom-Y-Nom'+Self-Z where Nom $=$ Nom' = a nominal, and where Nom and Nom' are within the same simplex sentence. [i.e., there is no S node between Nom and Nom', and Nom is a nominal, here, an NP]

(Lees \& Klima 1963: 23)

Pronominalisation applies to the output of Reduplication. The variable $Y$ between the Nom terms in L\&K's formulation in (26) has the value Ø; what we have, then, is:

27) a. $X-N o m-Y$

b. $\mathrm{X}-\mathrm{Nom}+$ Nom' $-\mathrm{Y}$ (via Reduplication)

c. $\mathrm{X}-\mathrm{Nom}-\mathrm{Nom}+\mathrm{Self}-\mathrm{Y}$ (via Reflexivisation)

The derivation we propose for adnominal and adverbial intensives is compatible with observations in Safir (2004: 206)

Only English [of the Germanic languages he considers], however, requires the adverbial-emphatic SELF form to be in construction with a pronoun, which I take to be evidence that the anaphor is a morphological compound in English that amounts to an $\mathrm{X}_{0}$ form

Consider now the following examples:

28) a. John executed Bill himself

b. John himself executed Bill

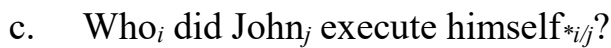

d. Who did John himself execute?

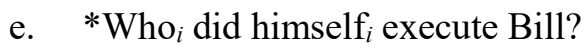

f. Who $_{i}$ executed Bill ${ }_{j}$ himself $_{i}$ ?

g. Who himself executed Bill? 
In this context, (28c) (with the relevant coindexing) and (28e) are excluded as violations of the Left Branch Condition (Ross 1967: 207 ${ }^{11}$ ); this is consistent with Leskosky's (1972: 50) claim that intensives are subjected to Ross' constraints. However, the only way to avoid an LBC violation in (28f) is to have Extraposition applying before Whmovement, so that the derivation proceeds as in (29) (we will assume that the transformation that gives us who from $\mathrm{N}+W h$, called $\mathrm{T}_{w 2}$ in Chomsky 1957: 112, applies very early in a derivation, possibly as soon as its structural description is met):

29) a. [s N+Wh executed Bill] (deep structure)

b. [s Who executed Bill] (via $\mathrm{T}_{w 2}$ )

c. [s Who himself executed Bill] (via Reduplication)

d. [s Who $t_{i}$ executed Bill himself $f_{i}$ (via Extraposition)

e. $\left[\mathrm{s}^{\prime} \mathrm{Who}_{j}\left[\mathrm{~s} t_{j} t_{i}\right.\right.$ executed Bill himself $\left.f_{i}\right]$ (via Wh-movement)

If we first extrapose SELF, then the configuration in which an LBC violation would arise simply disappears. In contrast, (28e) is the string resulting from applying Whmovement and not Extraposition, plus the late-insertion of do-support. It is worth pointing out that if we have a base-generated auxiliary (e.g., a modal), we can lower SELF locally early in the derivation, which produces a grammatical string (we will formulate the specific rule involved in this case in (36) below):

(28 e') Who would himself execute Bill?

The crucial thing here is that would, unlike $d o$, is present at deep structure and can thus be targeted by the rule we will call SELF-lowering.

Extraposition must be distinguished from a distinct lowering rule that applies in cases where a non-reflexive SELF appears within a sequence of auxiliary verbs, just like a floating quantifier or an intensifier like 'even' would (see Ross 1991: 461) $)^{12}$ :

30) a. John may himself have been being followed by the FBI

b. John may have himself been being followed by the FBI

11 Ross' formulation makes specific reference to NPs: "No NP which is the leftmost constituent of a larger NP can be reordered out of this NP by a transformational rule".

The LBC can be generalised, however: McCawley (1998: 526) reformulates it as follows:

"The Left Branch Constraint (LBC) [...] excludes extraction of or from the X of an [X Y] constituent".

In this way, if QPs are distinguished from NPs, sentences like *How many did you buy books? are also adequately excluded.

12 We are indebted to Haj Ross (p.c.) for providing these examples. The judgments in (30) are his. Some speakers may find (30b) to be marginal (but 'imaginable'), however, the contrast with (30c) and (30d) is clear even to them. 
c. ?John may have been himself being followed by the FBI

d. ??John may have been being himself followed by the FBI

Leskosky himself (1972: 52) noted similar examples, but restricted to periphrastic verbs rather than sequences of auxiliary verbs. There, the contrast between the adnominal and the adverbial reading are perhaps easier to note (Leskosky's examples 58, 59, 61, 62; judgments are his):

31) a. I have myself found numerous examples of this phenomenon.

b. Ralph Nader could himself be a presidential candidate in ' 72 .

c. You can yourself see that this is true.

d. You may yourself leave now.

Leskosky distinguishes It-Extraposition from Intensive-Extraposition, in that only the former is limited to targeting the periphery of a clause. It is essential to note now that the SELF that appears inside sequences of auxiliaries keeps its adnominal semantic value: in (30) and (31) we are not dealing with the semantics of adverbial intensives. Clearly the designation adnominal is incorrect, in view of the possibility of 'lowering' SELF through a sequence of auxiliaries while its original semantic value is maintained. We will refer to this local form of extraposition as SELF lowering (a designation that reminds the reader of Guy Carden's 1968 Quantifier Lowering, or at least I hope it does), and because this SELF can appear in positions other than juxtaposed to the nominal that is reduplicated, we will slightly change its name: instead of adnominal, we will refer to it as abnominal SELF (from $a b$-, Latin for 'from, off, away'): abnominal SELF originates - like adverbial SELF - via Reduplication and Reflexivisation, but an optional (cyclic) transformation SELF-lowering can apply, which moves it away from the nominal.

For the simple cases in (31), in Aux $+\mathrm{V}$ structures with only one Aux modifying the main $\mathrm{V}$, we can have either of the following sequences,

32) a. N-SELF - Aux - V

b. $\mathrm{N}-\mathrm{Aux}-\mathrm{SELF}-\mathrm{V}$

where all symbols are terminals. But, as we saw in (30), not all positions are available when we have longer sequences of auxiliary verbs. The restrictions in (30) seem to follow the generalisation in Ross (1991: 460ff.) that - in English 'niches' (structural positions where elements like adverbs and quantifiers can be inserted) get 'smaller' as we get closer to the verb, which means that the closer we are to the lexical verb, the stricter the restrictions on intruding elements. Interestingly, it seems to be the case that the restrictions on abnominal SELF are 
the same as the restrictions on the insertion of even, only, and also (with which SELF shares elements of meaning, as we can see in the paraphrases above) in the same contexts: acceptable after tensed auxiliaries and non-finite have or be, and unacceptable (to varying degrees) after been and being.

SELF lowering and SELF Extraposition (Extraposition, for short), which cannot both apply in the same derivation - for obvious reasons -, operate differently and generate different structures with different meanings. SELF lowering is a cyclic rule, like Quantifier Lowering. Extraposition has to be lastcyclic (Ross 1967: 274), targeting a position in the outermost cycle. We will now formulate the rules, so as to make them explicit:

33) SELF Extraposition:

$\begin{array}{cccc}{[\mathrm{s}[\mathrm{N}-\mathrm{SELF}]-\mathrm{VP}} & -\mathrm{X}] \\ 1 & 2 & 3 & 4 \\ 1 & \varnothing & 3+2 & 4\end{array} \Rightarrow$

(I assume, with Culicover \& Jackendoff 2005, particularly Chapter 4, among many others, that the grammar allows for multiple branching; sequences of VP adjuncts in which no scope arises are examples of this: John bought a book in the bookshop on Friday for £10. The lack of scope - which entails the lack of asymmetric c-command as per Ladusaw 1980, May 1985, and subsequent work - can be probed by changing the order of the adjuncts: the meaning of the sentence remains untouched as do its truth conditions. The finite-state structure described by $n$-ary branching seems to be necessary as well to provide adequate accounts for the syntax of iteration and instances of reduplication, as noted in Lasnik 2011; Krivochen 2015; Schmerling 2018. Thus, we do not need to invoke a further VP layer to accommodate adjuncts as we would in a strictly binarybranching version of the X-bar theory or current Merge-based proposals.)

For example:

33') a. [s [Np N SELF] $[\mathrm{vp} \ldots \mathrm{V} \mathrm{X}] \mathrm{s}] \Rightarrow$

b. [s [NP N] [vp ...V X SELF] s]

a'. I myself have formulated an ST-style transformation after the framework's fall from grace $\Rightarrow$

b'. I have formulated an ST-style transformation after the framework's fall from grace myself

The variable $\mathrm{X}$ stands for other extraposed elements: adverbial SELF may appear after VP adjuncts like [after the framework...], which are base-generated as daughters of VP, but it does not seem to be able to appear after extraposed NPs (which are adjoined to S; see Kroch \& Joshi 1987: 129ff.) or Ss, as shown in (34) 
34) a. * $\operatorname{John}_{i}$ talked to $\operatorname{him}_{j}$ yesterday, [NP the boy who's always following us] $]_{j}$ himself $_{i}$

a'. $\mathrm{John}_{i}$ talked to $\operatorname{him}_{j}$ yesterday himself ${ }_{i}$, [NP the boy who's always following us $]_{j}$

b. * $\operatorname{Ivan}_{i}$ figured it out that the bridge would hold himself (ungrammatical $^{\text {(ung }}$ in an intensive reading, example adapted from Ross, 1967: 276)

b'. $\quad \operatorname{Ivan}_{i}$ figured it out himself $i$ that the bridge would hold

As for the extraposition of relative clauses, Ross (1967: 285) orders the rule of Extraposition from NP after Extraposition, which correctly predicts that the extraposed SELF should appear before extraposed relative clauses:

35) a. *The postdoc ${ }_{i}$ did all the paperwork whose salary is not nearly enough herself $_{i}$

b. The postdoc $i$ did all the paperwork herself $f_{i}$ whose salary is not nearly enough

Let us now turn to the formulation of the rule SELF Lowering, which applies to abnominal SELF:

36) SELF Lowering:

$\begin{array}{cccc}{[\mathrm{s}[\mathrm{N}-\mathrm{SELF}]} & -[\text { Aux } \mathrm{X}-\mathrm{VP}]] \\ 1 & 2 & 3 & 4 \\ 1 & \varnothing & 3+2 & 4\end{array} \Rightarrow$

where $\mathrm{X}$ is a variable ranging over Aux elements: modals (will, would, may, might, can, could), have, passive $b e^{13}$. Note that because the structural description for SELF Lowering can be met if we have a modal at deep structure, example (28e') above is correctly predicted to be grammatical, unlike the do-support case (28e) (do-support is usually assumed to be late-inserted as a last resort to save crashing structures at the cost of violating Full Interpretation; see e.g, Grimshaw 2006). If SELF Lowering is a cyclic rule, the structure for sequences of auxiliaries could be as in Ross (1969). It is this operation that is sensitive to the size of 'niches' in the auxiliary system, which we noted above.

For example:

36') a. $\quad[\mathrm{s}[\mathrm{NP} \mathrm{N}$ SELF $][\ldots \mathrm{X} \ldots[\mathrm{VP} \ldots \mathrm{V}]] \mathrm{s}] \Rightarrow$

b. $[\mathrm{s}[\mathrm{NP} \mathrm{N}][\ldots \mathrm{X}+\mathrm{SELF} \ldots[\mathrm{vp} \ldots \mathrm{V}]] \mathrm{s}]$

13 We are indebted to Susan Schmerling for the discussion about this point and the examples we use in $(38 \mathrm{a}-\mathrm{d})$ below. She is not responsible for what we have done with them. 
a'. I myself have formulated an ST-style transformation after the framework's fall from grace $\Rightarrow$

b'. I have myself formulated an ST-style transformation after the framework's fall from grace

But further restrictions must be set: SELF Lowering does not work with:

37) a. The modal auxiliary need

b. Negated modals (including need)

c. Negated have and be

d. Progressive be

We illustrate these restrictions in (38), bearing in mind that judgments apply only to the abnominal interpretation:

38) a. *John needs himself to leave now (inflected need)

b. *John needn't himself leave now (negated need)

c. *John will himself not leave now (negated modal)

d. *John can't himself leave now (negated modal - contracted form)

e. *John $\left\{\begin{array}{c}\text { better } \\ \text { would rather }\end{array}\right\}$ himself not leave now (negated modal; see Schmerling, 1983)

f. *John wasn't himself questioned by the FBI (negated be)

g. *John hasn't himself left yet (negated have - contracted form)

h. *John is himself going now (progressive be)

It can be argued that need differs from canonical modals in that there is no niche after need, such that even in John needn't leave now (where need can host negation just like a garden-variety auxiliary can) there is no structural position where a SELF could be lowered between need and leave. If the issue with need is the absence of niches, then this is all we need to say about it for the purposes of this work. We have seen that Extraposition needs to apply after Passivisation when the intensive appears in the object NP, so as to comply with the subject condition above (the requirement that Extraposition cannot take place unless the nominal antecedent is in the subject position). That means that when we consider Wh-movement as well, the rule ordering for a sentence in which the object NP contains an intensive SELF (which is derived via Reduplication > Reflexivisation) must be: 
39) Reduplication $>$ Reflexivisation $>$ Passivisation $>$ Extraposition $>$ Whmovement ${ }^{14}$

The justification for this ordering is that Passivisation takes the object NP and makes it the surface subject, then Extraposition takes the right branch and moves it (so no LBC violation arises), and, last but not least, Wh-movement fronts the Wh-element (which is the left branch of the reduplicated NP). The question is: does this ordering generate a grammatical surface structure? (we will use Mary as the deep structure subject so that it cannot be a potential antecedent for the ED himself due to a gender feature mismatch):

40) a. Mary executed Bill (deep structure)

b. Mary executed Bill Bill (via Reduplication)

c. Mary executed Bill himself (via Reflexivisation)

d. Bill himself was executed by Mary (via Passivisation)

e. Bill was executed by Mary himself (via Extraposition)

(40e) is an unacceptable Surface Structure on an intensive reading. Now we can ask, does the situation improve with a Wh-word?

41) a. Mary executed $\mathrm{N}+W h$ (deep structure)

b. Mary executed who (via $\left.\mathrm{T}_{w 2}\right)$

14 This is a good time to address a challenge proposed by Haj Ross (p.c.), which is how to deal with the ungrammaticality of (i):

(i) *It was tough to give John money himself

In the view proposed here, in which we have Reduplication > Reflexivisation as the common initial steps for both adverbial and abnominal intensives, the derivation would proceed as follows:

a. It was tough to give money to John

b. it was tough to give money to John John (via Reduplication)

c. it was tough to give money to John himself (via Reflexivisation)

d. John himself was tough to give money to (via Pronoun Replacement)

At this point, the structural descriptions both for SELF-lowering and SELF-extraposition are met, so either can apply:

e. John was himself tough to give money to (via SELF-lowering, which seems to be a cyclic rule)

f. John was tough to give money to himself (via Extraposition, which seems to be a lastcyclic rule)

It seems to be the case that Dative Shift bleeds both SELF-lowering and Extraposition, but also if the derivation goes as I suggested above, then the intermediate representation $(\mathrm{g})$ :

g. *it was tough to give John money himself (= (i))

is simply not derived, because it would require Extraposition to apply before Pronoun Replacement. And since Extraposition can only apply if the target is a surface subject, $(\mathrm{g})$ is adequately blocked. 

c. Mary executed who who (via Reduplication)
d. Mary executed who himself (via Reflexivisation)
e. Who himself was executed by Mary (via Passivisation)
f. Who was executed by Mary himself (via Extraposition)

The same result obtains: (40e) and (41f) cannot be understood intensively. However, (41f) is not bad to the point that it is impossible to rescue, so the question arises: why is this so? And how exactly is (41f) interpreted in the rescued version? The answer, we argue, is to be found in the interaction between syntax and semantics.

\section{A further class of pseudo-reflexives}

As indicated above, we can indeed provide a context in which (41f) works:

42) Mary is an international assassin, and her latest mission is to kill John and Bill. Bill tried to warn John, who received a bullet in the head. Later on that day, Bill was executed by Mary himself.

It is clear that the ED is not an intensive in this case. We introduced Bill in the previous discourse so as to make the passive more natural (as natural as it can sound), but it seems clear that the Wh-form simply would not work:

42') ?? Mary is an international assassin, and her latest mission is to kill John and someone else. John received a bullet in the head, and later on that day, who was executed by Mary himself?

There is an explanation for this if we consider our earlier claim that only specific NPs can co-occur with intensives, not merely definite NPs. Of course, we now need to provide a definition of specificity. Here, we follow Enç (1991) in distinguishing definiteness from specificity, such that indefinite NPs can be specific when they have scope over operators other than quantified NPs (in which case scope ambiguities arise), as in (43):

43) a. Sarah didn't see a hanger lying on the floor, and she tripped and fell.

b. Helen must beat an athlete from UCLA who is trained by the Dogar brothers.

c. Jack wants to train with a famous weight lifter who has won many prizes

(examples from Enç 1991: 1) 
Ioup (1977: 234) defines specificity as 'having a particular object in mind', which, as (43) illustrates, can be achieved with indefinite NPs. Thus far, it seems to be the case that requiring a specific antecedent is the only reliable property that is common to all instances of intensive SELF.

The same seems to be the case with indefinite NPs with a generic interpretation (see also the examples in (6)):

44) An engineer should know this himself (Gast \& Siemund 2006: 350)

When a generic NP subject co-occurs with the abnominal SELF, the relevant predicate in fact applies to all members of the set (say, of engineers, in (44); i.e., not to the set as a whole ${ }^{15}$ ): for every $x, x$ an engineer, $x$ should know whatever the speaker has in mind ${ }^{16}$. What is the relation between the subject NP and the $\mathrm{ED}$ ? We think this puzzle is related to another involving quantification. It is a classic observation that sentences with more than a single quantified NP are ambiguous:

45) Every girl kissed a boy

a. Surface-scope: $\forall>\exists$

b. Inverse-scope: $\exists>\forall$

On the inverse-scope reading, there is one boy per girl; the sentence thus describes a one-to-one (a bijection) relation between the sets of girls and boys. Mutatis mutandis, this is what happens in (44): An engineer denotes, in fact, a set of individuals, each of whom should know something himself. The scope relation that emerges, thus, is himself $>$ an engineer, which is the same inverse-scope interpretation as in (45b).

Going back to some earlier examples which we left unaccounted for, what exactly is this SELF which can save (40e) and (42) ('Bill was executed by Mary

15 Note that 'an engineer' in (44) does not denote a kind; rather, it seems to be a characterising generic (in the sense of Krifka et al. 1995). It is also important to point out that (44) does not have a taxonomic reading, insofar as $a$ cannot be replaced by some while maintaining the same meaning (Cohen 2001: 186).

16 A reviewer points out that 'know this', as an inherently distributive predicate, could not possibly even in principle apply to the set as a whole in any structure (regardless of the presence of 'himself'). It is tricky to maintain the singular subject and modify the predicate appropriately. To test our claim, we can replace the predicate in Gast \& Siemund's work for one in which a distributive and a collective reading are in principle possible:

(i) Ten engineers are planning a bridge themselves

In the collective interpretation, there should be a single bridge; in the distributive one, there should be ten bridges. According to our informants, the collective interpretation is not available; this is thus consistent with our characterisation of intensives. 
himself') from unacceptability? And, how does it differ from the other intensives? Let us take a look at some further examples:

Context: Susan says that John saw Bill yesterday, and...

46) a. ...* Mary ${ }_{i}$ says [s that John saw Bill herself ${ }_{i}$ yesterday] (adapted from Safir 2004, judgment ours)

b. ....Mary ${ }_{i}$ herself $_{i}$ says [s that John saw Bill yesterday]

c. ....Mary $i$ says [s that John saw Bill yesterday] herself $i$

We see that a full embedded $\mathrm{S}$ does not count as an intervening node. The adverbial distribution can ignore a self-contained domain ${ }^{17}$, be it a full-fledged $\mathrm{S}$ or a pro-form:

d. ...Mary says $_{\text {that }}\left\{\begin{array}{c}\text { so } \\ \text { thaself }\end{array}\right.$ (with the same meaning as $(46 \mathrm{c})$ )

This SELF presents some very interesting properties. Consider the following example:

47) Mary deduced that Susan was cheating on Bill herself

(47) is ambiguous, insofar as it can mean:

47') a. Without any help, Mary deduced that Susan was cheating on Bill (Mary $=$ herself)

b. Mary was cheating on Bill, and she deduced that Susan was cheating on him as well (Susan $=$ herself)

(47’ b), we need to note, involves a conventional implicature (Grice 1975) namely, that Mary was cheating on Bill - which (47' a) does not. SELF seems to have an extra value, which is not adequately captured in any of the three categories above: SELF can be used to generate conventional implicatures, such that a property or eventive predicate which appears in the first conjunct of a coordinated structure is interpreted as distributed with respect to the subjects of both (thus, and rather unimaginatively, I will refer to this as a distributive SELF). That is, more or less formally (and simplifying a bit):

$$
p(a) \wedge b+\mathrm{SELF} \rightarrow p(a) \wedge p(b)
$$

17 In Krivochen (2017) we defined a 'self-contained' domain as a domain that does not dominate, nor is it or any of its terms dominated by, a non-root node in a separate domain. 
Here, $p$ is a predicate and $a$ and $b$ are NPs in 'structurally parallel positions' (in the sense of Goodall 1984: 85). That is: there is a property $p$ holding of an individual $a$ and that predication $p(a)$ co-occurs locally with an individual $b$ that has an associated SELF. For distributive SELF, the interpretation is that $p$ holds of both $a$ and $b$ (as in $\left(47^{\prime} \mathrm{b}\right)$ ).

For example:

48) John's an amazing cook, but I'm not bad myself (= I am also an amazing cook)

The relevant predicate here is 'be a good cook', $a=J o h n$ and $b=$ myself. Note that the SELF that generates a conventional implicature does not work well with comparatives, which suggests that the appropriate interpretation for something like (48) is 'I am at least as good as John', but exactly how good a cook I am is possibly left to conversational implicature (that is, in the interaction between the utterance and a particular context).

49) a. ??John's an amazing cook, and I'm better myself

b. *Mary's very pretty, but Sue's prettier herself (cf. Mary's very pretty, and Sue's very pretty herself / Sue's not too shabby herself)

The distributive SELF works very well in combination with litotes, as we see in (49). It does, of course, present some restrictions. It is particularly interesting to see its interactions with transformations that delete material under identity, like Gapping (Ross 1970) or Stripping (Hankamer 1971):

50) *John drank ten beers at the party last night, and Bill drank fifteen shots of vodka himself at the party today (Gapping)

51) *John drank ten beers at the party last night, and Bill drank ten beers himself at the BBQ today (Stripping)

Note that the examples in which distributive SELF works best are those in which the VPs in both clauses are parallel in Goodall's sense (Goodall 1984). But that is not all. There are also semantic-pragmatic considerations to bring to the table:

52) \#Mary executed John, and Susan executed Bill herself

It is almost impossible to get (52) to read like a distributive SELF, because the events denoted by the VPs are distinct, and they cannot be distributed over the subjects of the coordinated terms Mary and Susan ((47) can, however, receive an extraposed abnominal reading, in which SELF has no relation to the first conjunct; 
rather, it is derived via Reduplication, Reflexivisation, and Extraposition of Susan in the second conjunct, locally). Compare (52) with (53) in this regard:

53) Mary stabbed John, and Susan stabbed John herself

(53) is paraphrasable as 'Susan also stabbed John'. In this sense, constraints on the VPs that can be distributed are not unlike constraints on comparative clause pairings (Hale 1970: 31):

54) a. *Mary bought more records than John is tall (Hale's (8))

b. Mary bought more records than John

Note that in (54b) it is not the case that John and Mary bought the same records (so there is a sloppy identity reading), but the VPs that undergo Comparative Deletion need to be identical, modulo sloppy identity. In this sense, that the VP identity condition holds for distributive SELF as well. In this context, the ungrammaticality of (50) and (51) is, we think, caused by the same identity violation as the one which causes the ungrammaticality of (54a) and the impossibility of getting a distributed reading for (52).

The distributive SELF also differs from the garden-variety abnominal and adverbial intensives in that it can appear as the subject of an absolute clause:

55) Himself a man of science, John had to verify Bill's results

(55) conventionally implicates (in the Gricean sense) that both Bill and John are men of science, as is to be expected from the use of the distributive SELF. We have already seen that it is impossible for either abnominal or adverbial intensives to be topicalised (both SELF are to be understood as having been fronted from either of the positions marked with $t$ in these examples):

56) a. *Himself $f_{i}$, John $\left(t_{i}\right)$ had to verify Bill's results $\left(t_{i}\right)$

b. *Myself, I $\left(t_{i}\right)$ need to double-check Bill's results $\left(t_{i}\right)$ to be sure

We must note that (56a) and (56b) are possible on the pronoun reading, with the $1^{\text {st }}$ person example being favoured in this case over the $3^{\text {rd }}$ person one ${ }^{18}$.

18 This preference, in my opinion, is pragmatic rather than syntactic; and it has to do with the fact that the dislocated 'pronouns' (in the sense of 'syntactic objects governed by Principle B', as in (14)) are related to the perspective of the speaker (recall we glossed the free topic $1^{\text {st }}$ person pronoun as 'as far as I am concerned'); it is to be expected that there should be a clash between a $1^{\text {st }}$ person introducing a $3^{\text {rd }}$ person perspective. 
The fact that the distributive SELF can appear as the subject of an absolute clause, whose predicate is distributed over the relevant participants in the main clause, provides further arguments that it is lexically inserted, not derived via Reduplication and posterior Reflexivisation.

In contrast to intensives, whose distribution is determined sententially, the distributive SELF can make reference to a predicate introduced in a different utterance, within an adjacency pair:

57) Bank employee: -Have a great afternoon Me: -And you have a great afternoon yourself

Note that the predicate that is to be distributed ('have a great afternoon') in the inter-sentential distributive SELF must be accessible within the tree whose root indirectly dominates the distributive SELF, such that the relevant predicate can be recovered. Thus, (57'), in which the root dominating SELF does not dominate the predicate to be distributed, is correctly excluded as a response:

57') \#?And yourself

Let us now see a case of the distributive SELF which involves sloppy identity without deletion:

58) Mary deduced that Susan was cheating on her husband herself

For completeness, let us list the possible interpretations for (58):

58') a. Mary was cheating on Mary's husband, and she deduced that Susan was cheating on Susan's husband (distributive reading)

b. Without help, Mary deduced that Susan was cheating on Susan's husband (Mary $=$ herself; Susan $=$ her)

c. ??Without help, Mary deduced that Susan was cheating on Mary's husband (Mary $=$ herself; Mary $=$ her)

Now we are ready to go back to (24b) and (25b), which we repeat here as (59) and (60):

59) John was given a diploma by Mary himself

60) John is amusing to Mary himself (Leskosky's (38))

In the context of the analysis of the distributive SELF, (59) and (60) find a natural place, should we provide appropriate contexts which introduce participants with 
respect to whom the predicates can be distributed. Such contexts for (59) and (60) could be as in (59') and (60') respectively:

59') Mary gave a diploma to every student who had gotten an A+ on the exam: Bill was given a diploma, Peter was given a diploma, and John was given a diploma by Mary himself

60') Bill cracks Mary up and he thinks he's the only one, but John is amusing to Mary himself

The SELF in (59) and (60) is not the intensive variant -which is derived via Reduplication, Reflexivisation, and Extraposition, in that order- but rather the distributive version, which is base-generated in the right periphery of the VP.

A distributive SELF, also, does not require the NPs it is associated with to be animate: we can reinterpret $(5 \mathrm{c})$ ('The building itself collapsed after the hurricane'), minimally adapted, with the appropriate context:

61) The hurricane destroyed the company headquarters: the parking lot was devastated first, and then the building itself collapsed

As in (49), (59') and (60'), if all clauses present an overt predicate, it is not required that the predicate to be distributed be identical in them all; what is required, however, that all the predicates be semantically and pragmatically compatible. Thus, we can have animate and inanimate participants linked by distributive SELF:

62) Thousands of people were killed when Al Qaeda crashed airplanes into the World Trade Center's twin towers, and the buildings themselves ultimately collapsed.

Here it is also important to note that a distributive SELF does not always receive primary stress: in (62), primary stress falls on 'collapsed', not on 'themselves' via anaphoric destressing (assign weak stress to anaphoric nodes; Schmerling 1976); in this way, the interpretation that both 'people' and 'buildings' collapsed (which is pragmatically anomalous) is avoided.

\section{Conclusions}

This paper has analysed and classified instances of non-reflexive SELF forms in English. The literature on so-called 'intensives' usually recognises two kinds of such items: adnominal and adverbial variants. Based on some derivational properties (some already noted in Leskosky 1972), we have argued that 
abnominal may be a better name for the former; furthermore, we provided arguments in favour of distinguishing a third class of non-reflexive SELF (which to the best of our knowledge is not dealt with in the literature): distributive SELF. The differences between abnominal and adverbial intensives, on the one hand, and distributive SELF on the other motivate a different kind of analysis for the latter: distributive SELF is an operator which has scope over VPs, not deriving transformationally from a reduplicated N. Pronominal uses of SELF (as in (8ac), ' $\mathrm{John}_{i}$ thinks that [Mary is taller than himself $f_{i}$ ') are also not Reduplicated but can be arguments - unlike distributives - and - unlike both distributives and intensives - can appear fronted as free topics (see (14), 'Myself, I wouldn't let John take charge in a million years'). Distributive SELF, finally, does not present the animacy requirement that intensive SELF does.

We can now summarise the properties of the ED we have looked at in tabular form:

\begin{tabular}{l|c|c|c|c|c}
\hline & Meaning & Argumental & $\begin{array}{c}\text { Locally } \\
\text { bound }\end{array}$ & Stressed & Generation \\
\hline $\begin{array}{c}\text { Abnominal } \\
\text { intensive }\end{array}$ & $\begin{array}{c}\text { Contrastive } \\
\text { identity (N, as } \\
\text { opposed to } \\
\text { other } \\
\text { paradigmatic } \\
\text { options) }\end{array}$ & No & Yes & Always & $\begin{array}{c}\text { Reduplication } \\
+ \\
\text { Reflexivisation }\end{array}$ \\
\hline intensive & $\begin{array}{c}\text { Uniqueness and } \\
\text { agency (N } \\
\text { alone, with no } \\
\text { assistance) }\end{array}$ & No & No & Always & $\begin{array}{c}+ \\
\text { Reflexivisation } \\
\text { Distributive }\end{array}$ \\
$\begin{array}{c}\text { Distribution of } \\
\text { a predicate } p \\
\text { over } \\
\text { participants in } \\
\text { separate clauses } \\
(p(a) \text {, and } p(b) \\
\text { also), or in } \\
\text { adjacency pairs } \\
\text { cross- } \\
\text { sententially }\end{array}$ & No & No & Always & $\begin{array}{c}\text { Lexical } \\
\text { Insertion }\end{array}$ \\
\hline $\begin{array}{c}\text { Coindexing of } \\
\text { two arguments } \\
\text { of a given } \\
\text { predicate }\end{array}$ & Yes & Yes & Not & always & Reflexivisation \\
\hline \multirow{2}{*}{ Reflexive } & & & & \\
\hline
\end{tabular}




\section{REFERENCES}

Bach, Emmon. 1970. Problominalization. Linguistic Inquiry 1(1). 121-122.

Baker, Carl Lee. 1995. Contrast, discourse prominence, and intensification, with special reference to locally free reflexives in British English. Language 71(1). 63-101. DOI: $10.2307 / 415963$

Bickerton, Derek. 1987. He himself: Anaphor, pronoun, or...? Linguistic Inquiry 18(2). 345-348.

Chomsky, Noam. 1957. Syntactic structures. The Hague: Mouton.

Chomsky, Noam. 1977. Conditions on transformations. In Noam Chomsky, Essays on form and interpretation. New York, NY: North Holland. 81-160.

Chomsky, Noam. 1981. Lectures on government and binding. Dordrecht, Foris.

Chomsky, Noam \& Howard Lasnik. 1994. The theory of principles and parameters. In Noam Chomsky, The Minimalist Program. 13-127. Cambridge, MA: MIT Press. DOI: 10.7551/mitpress/9780262527347.001.0001

Cohen, Ariel. 2001. On the generic use of indefinite singulars. Journal of Semantics 18(3). 183209. DOI: $10.1093 /$ jos/18.3.183

Culicover, Peter \& Ray Jackendoff. 2005. Simpler syntax. Oxford: Oxford University Press.

Enç, Mürvet. 1991. The semantics of specificity. Linguistic Inquiry 22(1). 1-25.

Gast, Volker \& Peter Siemund. 2006. Rethinking the relationship between SELF-intensifiers and reflexives. Linguistics 44(2). 343-381. DOI: 10.1515/LING.2006.013

Goodall, Grant. 1984. Parallel structures in syntax. Ph.D. thesis, University of California San Diego.

Grice, Paul. 1975. Logic and conversation. In Peter Cole \& Jerry L. Morgan (eds.), Syntax and semantics. Vol. 3: Speech acts, 41-58. New York, NY: Academic Press.

Grimshaw, Jane. 2006. Last resorts and grammaticality. In Hans Broekhuis \& Ralph Vogel (eds.), Optimality Theory and Minimalism: A possible convergence?, 33-41. Potsdam: Universitätsverlag.

Hale, Austin. 1970. Conditions on English comparative clause pairings. In Roderick A. Jacobs \& Peter Rosenbaum (eds.), Readings in English transformational grammar, 30-55. Waltham: Ginn \& Co.

Hankamer, Jorge. 1971 Constraints on deletion in syntax. Ph.D. Thesis, Yale University.

Hornstein, Norbert \& William Idsardi. 2014. A program for the Minimalist Program. In Peter Kosta, Steven L. Franks, Teodora Radeva-Bork \& Lilia Schürcks (eds.), Minimalism and beyond: Radicalizing the interfaces, 9-36. Amsterdam: John Benjamins.

Ioup, Georgette. 1977. Specificity and the interpretation of quantifiers. Linguistics and Philosophy 1(2). 233-245.

König, Ekkehard \& Volker Gast. 2002. Reflexive pronouns and other uses of 'self'-forms in English. Zeitschrift für Anglistik und Amerikanistik 50(3). 225-238.

König, Ekkehard \& Peter Siemund. 2000. Locally free self-forms, logophoricity, and intensification in English. English Language and Linguistics 4(2). 183-204. DOI: 10.1017/S1360674300000228

Krifka, Manfred, Francis J. Pelletier, Gregory N. Carlson, Alice ter Meulen, Godehard Link \& Gennaro Chierchia. 1995. Genericity: An introduction. In Gregory Carlson \& Francis Pelletier (eds.), The generic book, 1-124. Chicago, IL: University of Chicago Press.

Krivochen, Diego Gabriel. 2015. On Phrase Structure building and labelling algorithms: Towards a non-uniform theory of syntactic structures. The Linguistic Review 32(3). 515-572. DOI: $10.1515 /$ tlr-2014-0030 
Krivochen, Diego Gabriel. 2017. Syntax as graph theory. https://ling.auf.net/lingbuzz/003842

Kroch, Anthony S. \& Aravind K. Joshi. 1987. Analyzing extraposition in tree adjoining grammar. In Geoffrey J. Huck \& Almerindo E. Ojeda (eds.), Syntax and semantics 20: Discontinuous constituency, 107-151. New York, NY: Academic Press.

Ladusaw, William A. 1980. Polarity sensitivity as inherent scope relations. Bloomington, IN: University of Iowa, Indiana University Linguistics Club.

Lakoff, George. 1965. On the nature of syntactic iIrregularity. Ph.D. thesis, Indiana University.

Lasnik, Howard. 2011. What kind of computing device is the human language faculty? In Anna Maria Di Sciullo \& Cedric Boeckx (eds.), The biolinguistic enterprise: New perspectives on the evolution and nature of the human language faculty, 354-365. Oxford: Oxford University Press.

Lees, Robert B. \& Edward S. Klima. 1963. Rules for English pronominalization. Language 39(1). 17-28. DOI: $10.2307 / 410759$

Leskosky, Richard J. 1972. Intensive reflexives. Studies in the Linguistic Sciences 2(1). 42-65.

Levinson, Stephen C. 1991. Pragmatic reduction of the Binding Conditions revisited. Journal of Linguistics 27(1). 107-161.

May, Robert. 1985. Logical Form: Its structure and derivation. Cambridge, MA: MIT Press.

McCawley, James D. 1998, The syntactic phenomena of English. (2nd edn) Chicago, IL: University of Chicago Press.

Postal, Paul M. 1969. On so-called 'pronouns' in English. In David Reibel \& Sanford Schane (eds.), Modern studies in English: Readings in transformational grammar, 201-224. New Jersey: Prentice Hall.

Postal, Paul M. 1971. Cross-over phenomena. New York, NY: Holt, Rinehart \& Winston.

Quirk, Randolph, Sidney Greenbaum, Geoffrey Leech \& Jan Svartvik. 1985. A comprehensive grammar of the English language. London: Longman.

Reinhart, Tanya. 1983. Anaphora and semantic interpretation. London: Croom Helm.

Reuland, Eric \& Tanya Reinhart. 1993. Reflexivity. Linguistic Inquiry 23(4). 657-720.

Roberts, Craige. 2003. Uniqueness in definite noun phrases. Linguistics and Philosophy 26(3). 287 350.

Ross, John Robert. 1967. Constraints on variables in syntax. Ph.D. Thesis, MIT.

Ross, John Robert. 1969. Auxiliaries as main verbs. In William Todd, (ed.), Studies in philosophical linguistics, 77-102. Evanstown, IL: Great Expectations.

Ross, John Robert. 1970. Gapping and the order of constituents. In Actes du Xe Congrès international des linguistes, 841-853. Bucharest.

Ross, John Robert. 1991. Verbiness and the size of niches in the English auxiliary. In Carol Georgopolous \& Roberta Ishihara (eds.), Interdisciplinary approaches to language: Essays in honor of S-Y. Kuroda, 459-466. Dordrecht: Kluwer Academic.

Ross, John Robert. 2012. A preliminary, but fattened, list of transformations. http://wwwpersonal.umich.edu/ jlawler/haj/Preliminarybufattenedlistoftransformations.pdf

Safir, Ken. 2004. The syntax of anaphora. Oxford: Oxford University Press. DOI: 10.1093/acprof:oso/9780195166132.001.0001

Schmerling, Susan F.. 1976. Aspects of English sentence stress. Austin, TX: University of Texas Press.

Schmerling, Susan F. 1983. A new theory of English auxiliaries. In Frank Heny \& Barry Richards (eds.), Linguistic categories: Auxiliaries and related puzzles (vol. 2), 1-53. Dordrecht: Reidel. 
Schmerling, Susan F. 2018. Rhetorical meaning. Linguistic Frontiers 1(1). 55-64. DOI: 10.2478/1f2018-0001

Siemund, Peter. 2000. Intensifiers: A comparison of English and German. London: Routledge. 